\title{
Trident Mine Raisebore — A Bored Pile Case Study
}

\author{
M. Sexton Avoca Resources Ltd, Australia
}

P.A. Mikula Mikula Geotechnics Pty Ltd, Australia

M.F. Lee AMC Consultants Pty Ltd, Australia

\begin{abstract}
As part of bringing their new Trident gold mine into production, Avoca Resources Ltd had to construct two ventilation shafts (three and four metre diameters) through to the surface. Several zones of extremely weathered material and damp clays were present at both proposed shaft locations, including five metres of soft clay at one of the sites.

Single-pass conventional raiseboring was the most desirable method of construction (safest, quickest and cheapest), but this meant back-reaming through the weathered ground. Stability assessments suggested that the proposed raise diameters were unlikely to be suitably stable after reaming, even for a short period of time, prior to stabilising the freshly exposed weathered walls by remotely sprayed fibrecrete. Conventional raiseboring was therefore considered risky.

The risk of overbreak, failure and loss of the raises was minimised by installing a ring of non-contiguous, cable-reinforced grouted mini-piles through the problem zones before back reaming. Regardless of this preparation, there was a high awareness of the risk of failure while the raises were back-reamed through the weathered zones. The weathered sections were fibrecreted as soon as the raiseboring was completed.
\end{abstract}

The paper documents key aspects of the project, in particular design and operational aspects of the piles.

\section{Introduction}

Avoca Resources Ltd required two $150 \mathrm{~m}$ deep ventilation shafts, of three and four metre diameters, to be constructed as part of bringing their new Trident gold mine into production (Figure 1). As is typically the case in the Western Australian Yilgarn Craton, specific site investigation drilling confirmed about $50 \mathrm{~m}$ of weak weathered rocks (saprolites) at both sites, with sharp contacts to strong competent rocks below (Figure 2). In particular, at the site of the southern four metre diameter shaft, a five metre thick clay zone was present.

To minimise delays to underground mining at Trident, both shafts were needed quickly, and raiseboring was the proposed construction method. The presence of weak and wet saprolite at both ventilation shaft sites, in fact everywhere above the deposit at potential shaft locations, dictated that construction of the shafts would be neither simple nor easy. Empirical Q-based stability assessments of the saprolite at both sites indicated that the freshly exposed raise walls would not be sufficiently stable.

To reduce the risk of failure, various combinations of construction methods were considered. One option was to raisebore the fresh rock at the required diameter, but leave a pillar to the weathered material, then back ream a smaller raise through the weathered material, followed by sinking the top section of the shaft by stripping and concrete lining.

Another alternative, adopted by Avoca, was to improve the stability of the saprolite by installing rings of non-contiguous grouted reinforced mini-piles around the circumference of both raises. If correctly designed, these piles would, in theory, limit overbreak of the raise walls and allow raiseboring at the full diameter through to the surface in one pass. It was however critically important to quickly support the newly exposed weathered shaft walls, after the raisebore head was removed, by remotely spraying fibrecrete. Variations of this "ground improvement" method had previously been trialled at other Australian mines.

This paper documents geotechnical and operational issues associated with the construction of the four metre diameter Southern Primary Ventilation Shaft through the weathered zone at Trident. 


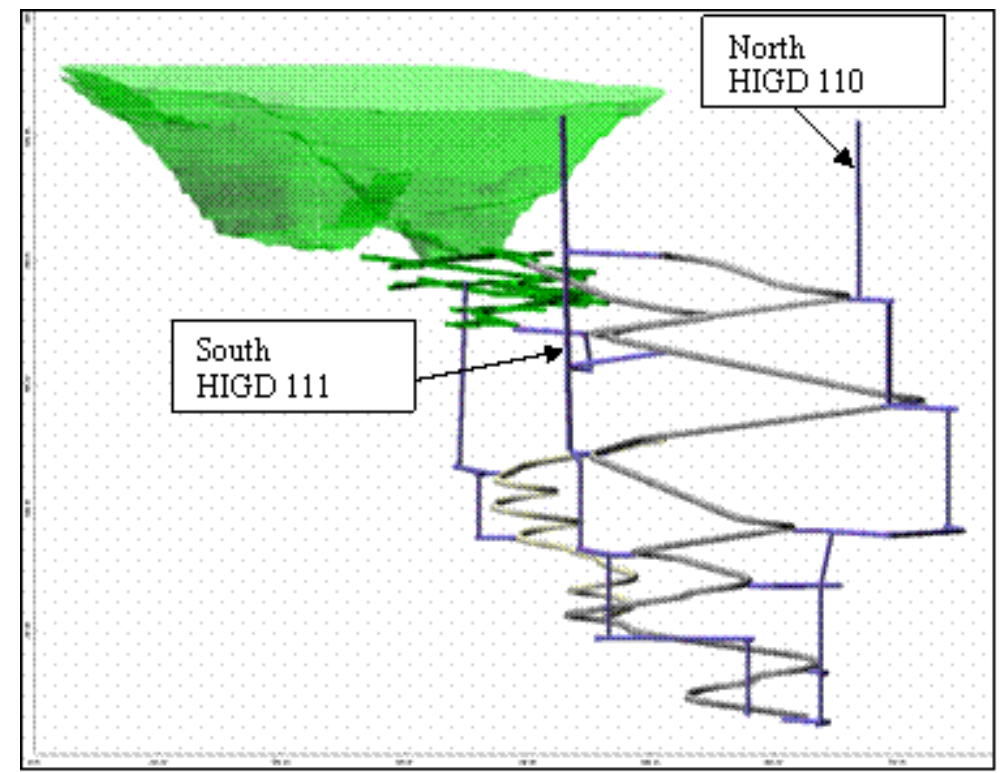

Figure 1 Location of the North and South raisebore sites. Also shown are the old Poseidon South pit shell and limited existing underground workings, and the notional layout of Trident Life of Mine development

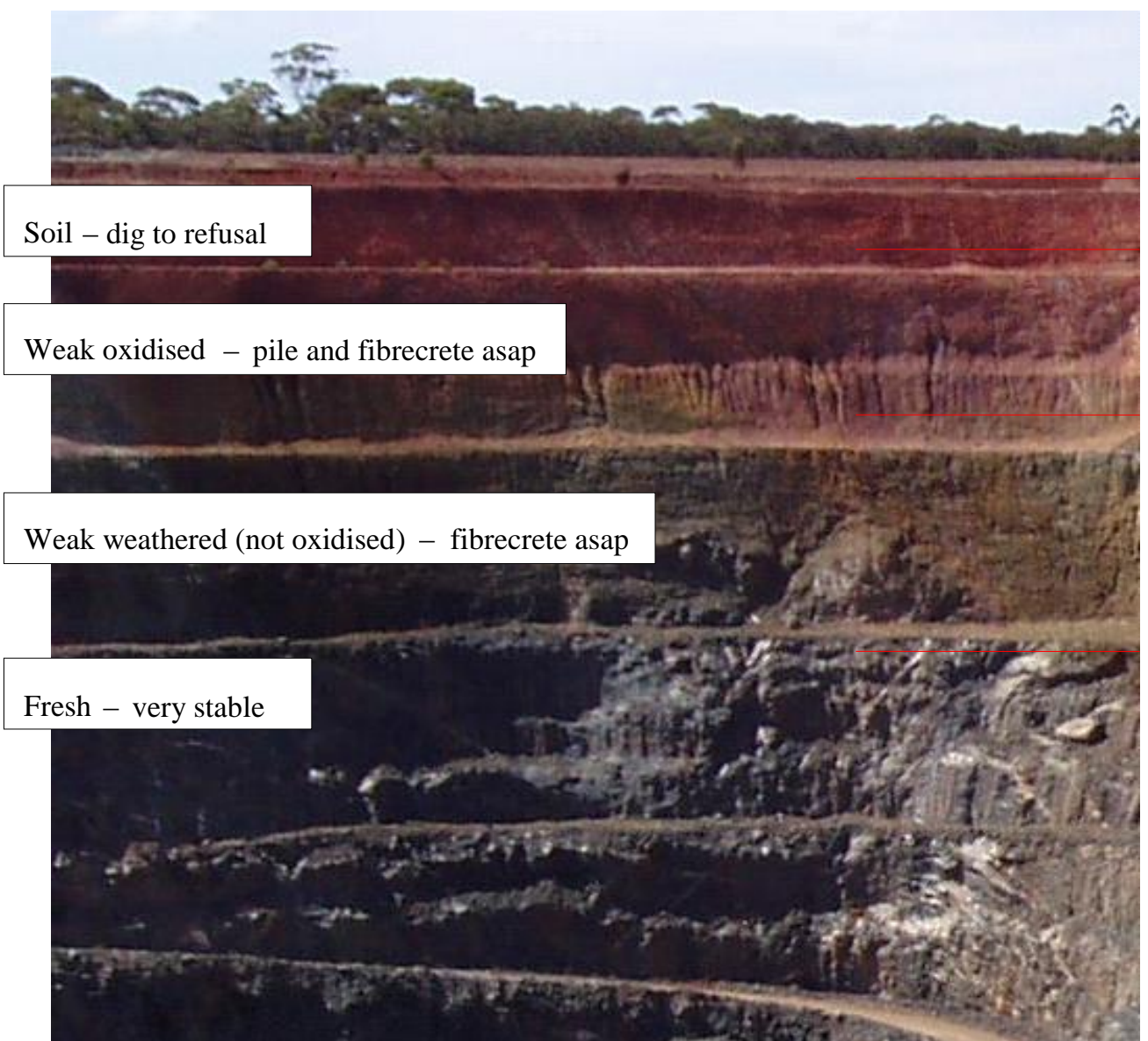

Figure 2 View of the northern wall of the Poseidon South pit, showing weathering intervals (soil, saprolite and fresh gabbro) and potential implications for raiseboring stability 


\section{Australian experience}

The preferred construction method for ventilation shafts in Australia is by raiseboring, ideally as a single pass through to the surface. While raiseboring has substantial benefits (safer, quicker and cheaper) over conventional shaft sinking, it has not been universally successful in Australia (Peck and Lee, 2008).

Typically for very long, large diameter raisebored shafts, the following stability issues needed to be addressed:

- At the bottom of deep raises there is the chance of high stress spalling from the advancing face and dog-earing of the raise walls. Both can affect the mechanical raiseboring process. The limited depth of the Trident raises and the high strength of the gabbro meant that this was not an issue at Trident.

- Thick moderately to steeply dipping faults, shears or broken zones can mean significant overbreak anywhere in the raise, of both the advancing face and the newly exposed walls. Apart from issues with the mechanics of raiseboring itself, in some situations this overbreak can lead to uncontrolled unravelling and loss of the shaft.

The McCracken and Stacey method is typically used in Australia to assess raise stability (McCracken and Stacey, 1989). It is essentially a modified version of the very popular empirical QSystem developed by Barton et al. (1974) to assess the stability of rock masses. More recently and under the sponsorship of the Eastern Australian Ground Control Group (EAGCG), Peck and Lee (2008) documented the Australian experience of raisebored shafts, including guidelines as to how general raise stability should be assessed, and relationships between actual stability versus ground conditions. In particular, it was concluded that neither the McCracken and Stacey method nor Barton's Q-System should be used to assess the stability of materials that are not rock like.

At both sites, the stability of the fresh competent Trident gabbro was not an issue, and the few faults present were moderately dipping, tight and under two metres thick.

- The stability of near-surface weathered rocks is always very difficult to assess, particularly for large raises, and especially when they intersect extremely weathered (e.g. clay rich), weak and wet materials.

Unfortunately, deep weathering seems to be a feature of the Australian landscape, and empirical methodologies for assessing the stability of raisebored shafts in these materials do not yet exist. These conditions are common in weathered Yilgarn greenstones. Numerous raises have been lost due to collapses in weathered materials, and collapses have often initiated in wet saturated zones just above the often sharp contact with fresh competent rock below.

Exactly these conditions were present at Trident.

\section{Shaft construction options}

Numerous shaft construction options have been used to manage risks of failure, especially of weathered rocks:

Pre-collar. Deep collars are often excavated and backfilled with cemented backfill, followed by wide thick concrete pads for the raisebore foundations.

Large diameter piling. At some mines, large pile boring machines have been used to excavate weak surface rocks, e.g. at Cannington (Figure 3). Piling up to about five metres diameter through weak weathered rock is possible, and civil engineers are now boring a few large piles rather than many smaller ones. Large piles are bored through to refusal. Pile wall stability is an issue, but it can be addressed in several ways, e.g. casing or progressive fibrecreting. The main constraint with large diameter piling is rig availability and mobilisation costs.

Alimak. Alimaks have been used to sink shafts by stripping floors into pilot holes or small raisebores. In a surface shaft sink, this would need a frame above the ground so the ratchet could climb up and the platform could exit the shaft. Walls are progressively meshed, fibrecreted and bolted as required on advance. This is 
similar to a conventional strip and line sink, except that a head frame is not required, nor a winder driver, nor a slip form liner.

Conventional surface sink. The most common method has involved sinking by stripping into a small diameter pilot hole and slip-form concrete lining. The procedure involves back-reaming up to about two diameters below the weathered ground, removing the raisebore head, then sinking from the surface perhaps by stripping into the pilot hole. Depending on local mining regulations, mobile cranes have been used, but a temporary headframe is typically required. The weathered interval is often concrete lined rather than just meshed and bolted.

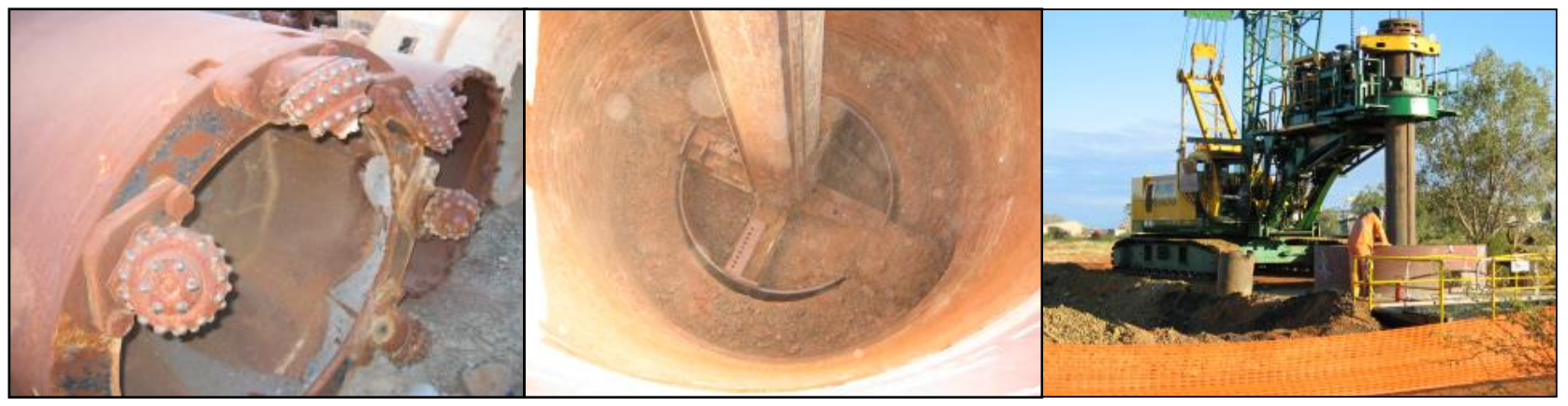

Figure 3 Large diameter piling technology

Small diameter reinforced bored piles. In recent times, arrays of reinforced non-contiguous mini-piles, positioned about $0.5 \mathrm{~m}$ outside the intended raise circumference, have been trialled in Australia. This is a cheap and perhaps riskier mining variation of the common civil engineering practice of installing large diameter, reinforced concrete contiguous piles to stabilise walls. The motivation is to improve near-surface ground conditions so that raises can be back-reamed full-face through to the surface, thus avoiding the need to use other methods in which personnel have to work in shafts.

Mining operations where arrays of piles have been trialled include at least the following: Bendigo Gold mines (reinforced mini-piles and large contiguous piles), Callie Gold mine (mini-piles reinforced with old diamond drill rods) and Mount Isa mine. Figure 4 shows an example of a ring of contiguous bored piles forming a curtain at another mine site. Other sites have used a range of pile diameters from 150-750 mm, some not contiguous.

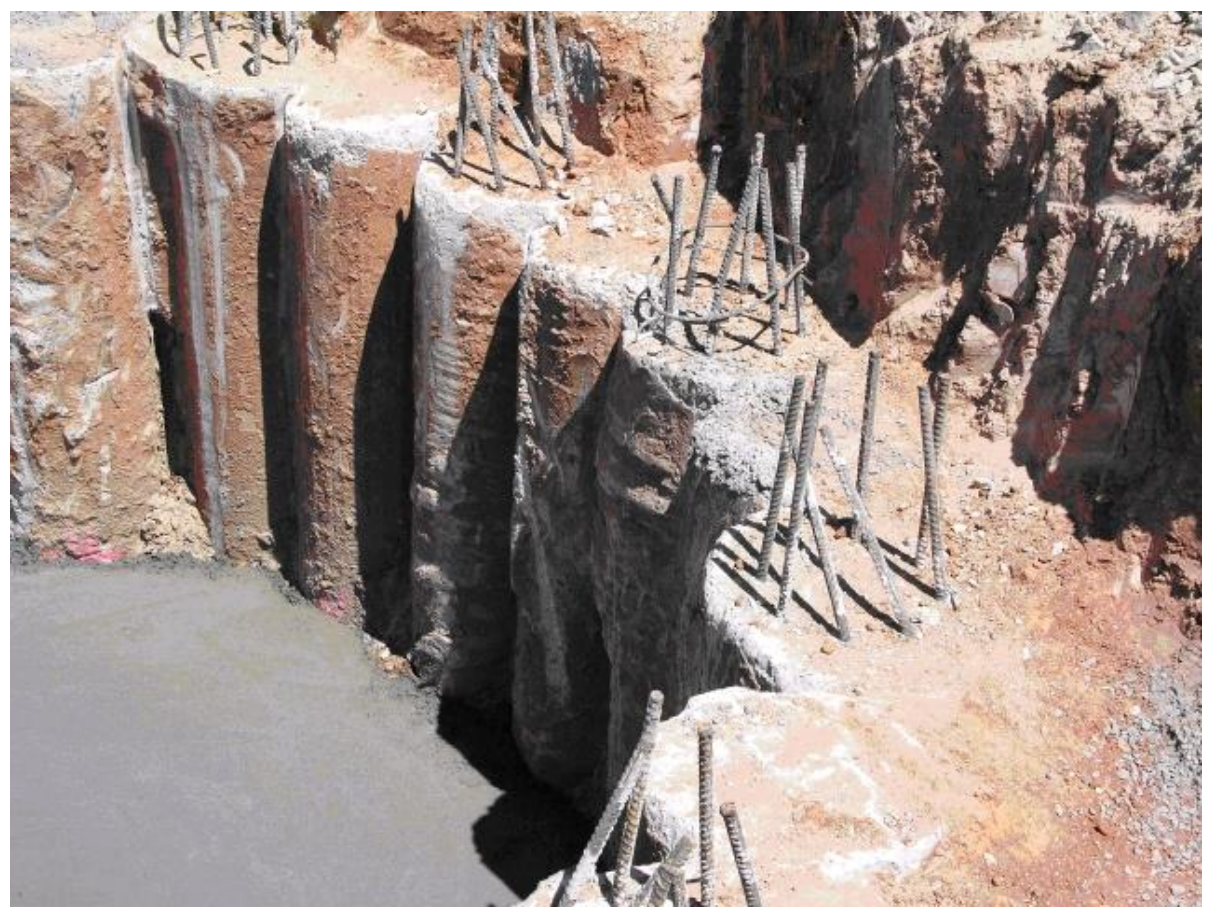

Figure 4 A ring of contiguous bored piles forming a curtain at another mine site 
Bored piles are an attractive support option for weathered zones. Avoca adopted this approach, but with noncontiguous piles. Geotechnical risks with the adopted approach were recognised: clays squeezing between the piles; piles displaced or broken by moving ground; fallout of wedges and blocks of weathered material during reaming damaging the raisebore head; unravelling of weathered material by progressive cracking or crumbling; piles wandering into the path of the shaft.

Liners. Remote spraying of fibrecrete has been increasingly used in Australia to improve the long-term stability of raises. Previously, slip-form concrete linings or steel cans were grouted over suspect sections of shafts, or the walls were manually meshed and bolted. However, all these methods require personnel working in the shaft, with associated hazards and regulatory requirements that the mine operator must manage effectively in the work place.

\section{Borehole core and open pit slope data}

While vertical site investigation boreholes were drilled at each planned raisebore site (Figure 1), this paper focuses on hole HIGD 111 for the four metre diameter southern shaft.

Borehole core. Fresh gabbro started at a depth of $50 \mathrm{~m}$ and posed no stability issues. Only the weathered zone was found to be of concern, due to the presence of soft wet clays (Figure 5) mainly over the zone 17-29 $\mathrm{m}$. The thickest single soft clay band, five metres thick, extended from 20-25 m depth. The clay zones were extensive, and their thicknesses were not small compared to the four metre raisebore diameter.

Apart from the usual geotechnical logging of core using Barton's Q-System, the fresh rock interval was logged using an acoustic televiewer. Logs of rock quality designation (RQD) and material strength index (Figure 6) were compiled.

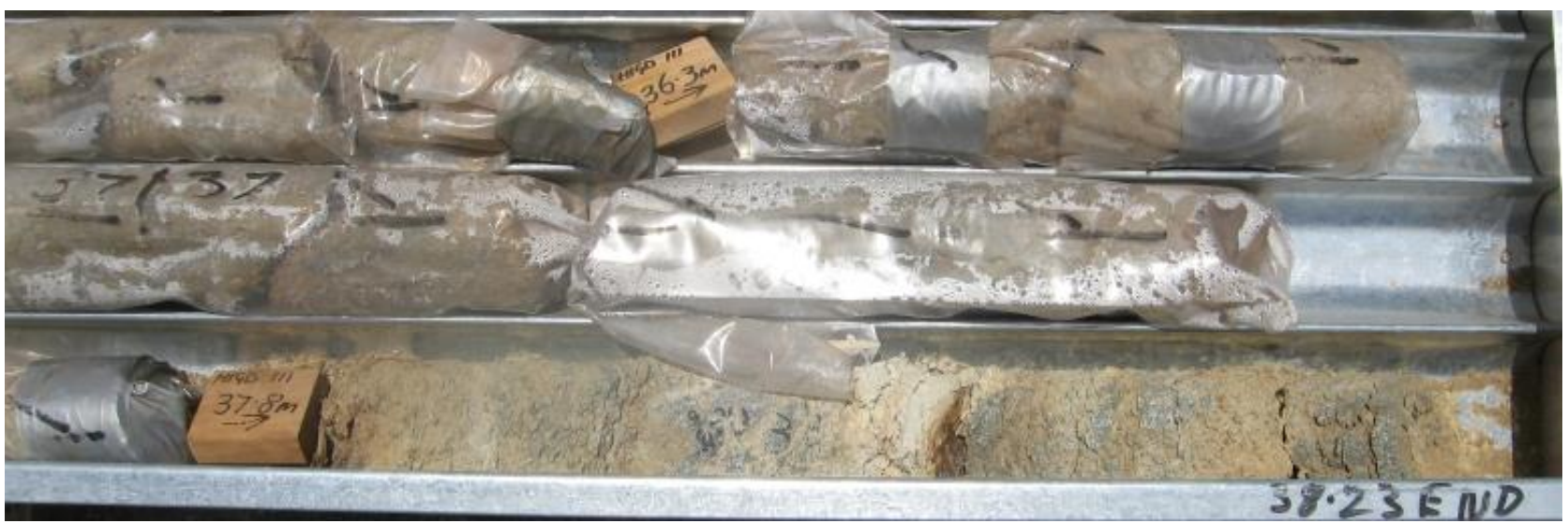

Figure 5 Drilled core from the HIGD 111 weathered zone. Highly weathered rock and clays are wrapped in plastic. Exposed material has severely degraded within a few weeks of drilling

Pit slopes. Indicative ground conditions, particularly over the weathered zone, and likely stability were also assessed from an inspection of the weathered slopes of the adjacent disused Poseidon South Pit (Figure 2). This survey collected valuable data on RQD, typical block size, the number of joint sets and joint condition.

RQD of the weathered exposures in the pit varied from 20-100, which compared favourably with the borehole logs. Block size varied from 0.1-2 $\mathrm{m}$. While the average block size was $0.6 \mathrm{~m}$, it was the smaller sizes that were a stability concern for the raises. A block size of $0.4 \mathrm{~m}$ was adopted for the stability assessment. The number of joint sets varied between three and three-plus a random set. As the 17 year old pit slopes showed very little evidence of erosion, it was considered that the clays were not dispersive in water.

\section{$5 \quad$ Raisebore stability analysis}

The Q-system of rock classification (Barton et al., 1974) was used to assess the stability of the raisebored shaft, rather than the more popular modified version by McCracken and Stacey (1989). Maximum stable unsupported span (MSUS) was considered to be adequate for the appraisal, and it was estimated for the shaft wall versus depth (Figure 7). Pit slope observations and borehole data were used to estimate MSUS. 

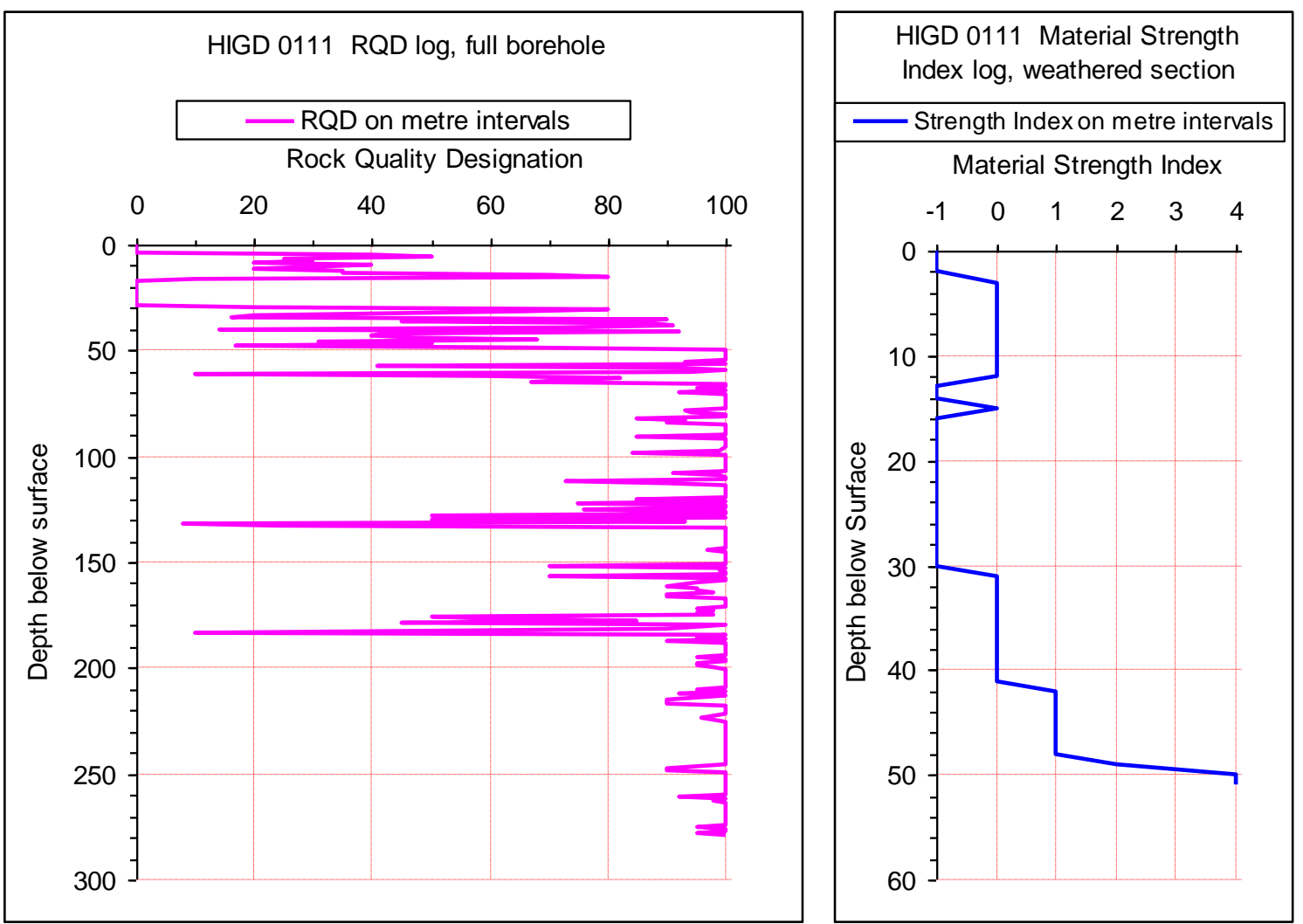

Figure 6 HIGD 111 core log data. Left: RQD log for full hole. Right: material strength index $\log$ for the weathered interval ( 0 and -1 indicate soil strength, 1-4 indicate rock strength)
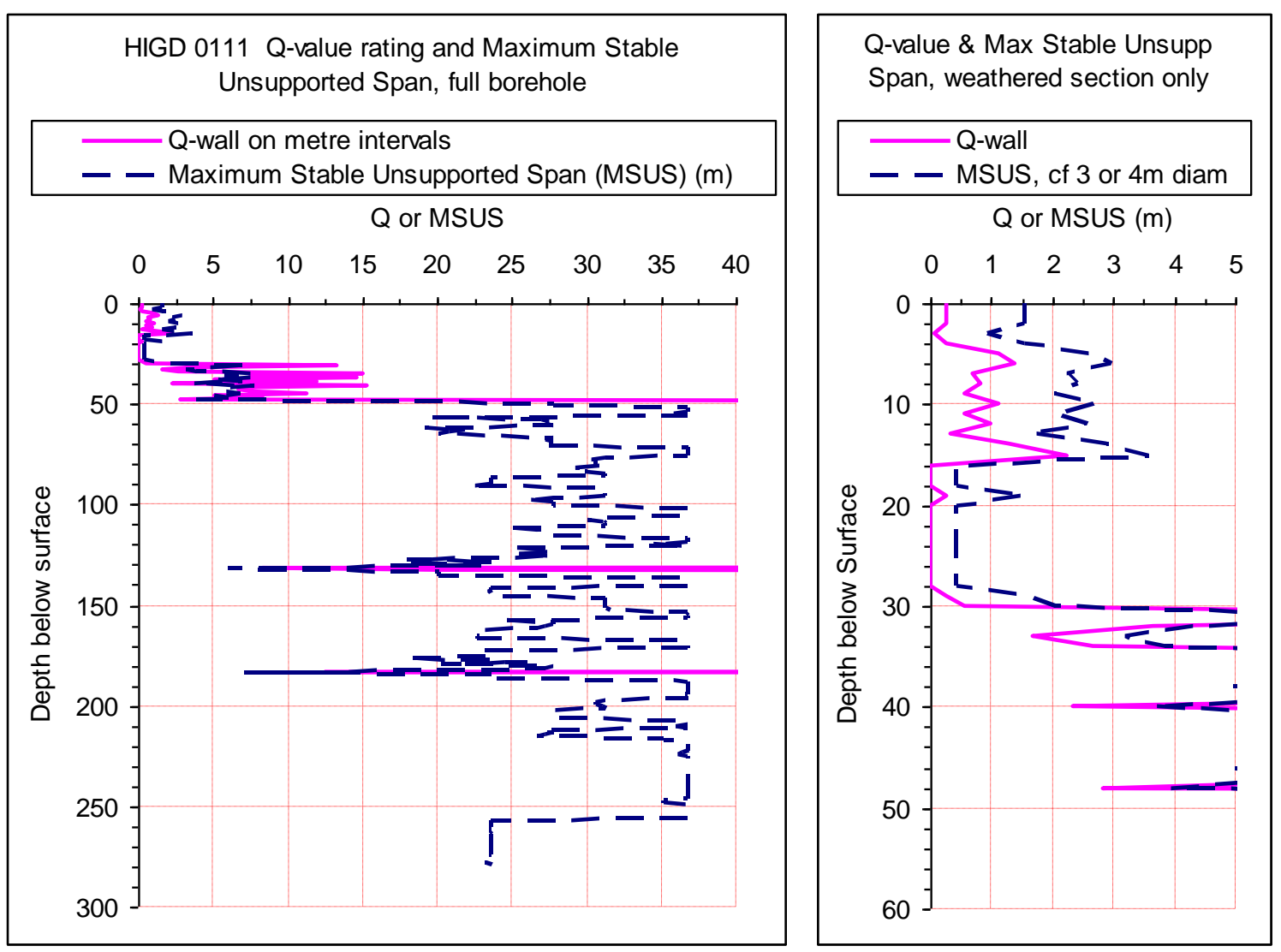

Figure $7 \quad Q$ and MSUS versus depth for HIGD 111 
Because the clay zones encountered in HIGD 111 was judged to be worse than any of the ground conditions exposed in the pit slope, high 'Ja' values of ten were used to estimate $\mathrm{Q}$.

Calculated Q and MSUS values are summarised in Figure 7 versus depth. The weathered zone is clearly the only zone of interest regarding the stability of the four metre diameter shaft. Note: As RQD should only be applied to 'rock-like' materials, Q does not strictly apply in weathered materials and soils (i.e. the clays at Trident). The field strength logging identified some intervals of soil-strength materials. The Q and MSUS values shown in Figure 7, for the weathered zone, are therefore only illustrative.

\section{Bored pile design}

Rings of non-contiguous piles were designed around the shaft position through the weathered zone, with cable dowels being grouted into some of these piles (Figures 8 and 9). Ideally they toe into fresh rock below. The piles were incorporated into the shaft cap, but they were de-coupled (using poly-casing) to allow vertical creep of the shaft cap relative to the piles, which was considered possible during back-reaming.

The most demanding situation for the stability of the freshly exposed wall was at the end of reaming, but before remote fibrecreting.

Pile diameter. Pile diameters used at other mine sites vary, mainly depending on what contractors can provide and on the expected drill deviation at depth. Larger diameter piles are more stable and preferred, particularly if they are not seated into fresh rock. Axially loaded small diameter piles are less stable against buckling, compared to larger diameter piles.

At Trident, 140 and $270 \mathrm{~mm}$ piles were used. The options were restricted by the available drilling equipment and contractors.

Pile spacing. The spacing between piles was specified to not exceed three times the $0.4 \mathrm{~m}$ block size in blocky ground. Thus pile centre spacing had to be no more than $1.47 \mathrm{~m}$ for $270 \mathrm{~mm}$ piles.

As the thick zone of clay in HIGD 111 was outside the block size categorisation, it needed to be separately physically restrained from slumping. The main risk of wall instability was in not knowing how close the piles needed to be to support the soft clay.

To help retain the soft clay a smaller inter-pile spacing was required, at least across the clay zones. This led to the design of a staggered configuration of alternately shorter and longer piles, with a $1.5 \mathrm{~m}$ spacing between long piles, and shorter piles between these through the main clay zone.

Pile length. The pile lengths needed to be sufficient to bed into fresh rock having a MSUS of about five or better, i.e. $44 \mathrm{~m}$ depth (see Figure 7). However, for staggered piles, only the longer piles needed be this long.

Number of bored piles. If the $270 \mathrm{~mm}$ bored piles centres were stood $0.5 \mathrm{~m}$ back from the edge of the raisebored shaft, then the minimum number of piles needed for blocky ground was 11 for the four metre diameter shaft. If the pile centres were only $0.15 \mathrm{~m}$ back from the shaft edge, the minimum number of piles was reduced by one.

The piles at the greater standoff distance had less risk of buckling, as the piles would be more supported by surrounding material.

Pile reinforcement options. Pile material composition options included strong concrete without reinforcing, a fibrecrete mix, or a lower strength concrete with steel reinforcing. A range of materials could be used as reinforcement within the bored grouted piles. Again, variations have been trialled at other Australian mines:

- Fibre glass dowels/cables where the holes wandered into the anticipated path of the raisebore.

- Solid $32 \mathrm{~mm}$ rebar, butt welded as each length is lowered into the hole. This would not become wrapped around the cutters if the steel was in the path of the raisebore head.

- Any easily salvageable steel can be used; e.g. old drill rods, if there is no chance of the head intersecting these piles.

- Bundle up small diameter steel or fibreglass to achieve the equivalent of larger diameters. 
Drilling accuracy. Deviation of the piles into the path of the raisebore was a concern.

Because it was not possible to use large diameter piles without reinforcement, the design had to be alternating or staggered piles; unreinforced close to the final raise walls and reinforced piles further away. Additionally, the piles at a $0.15 \mathrm{~m}$ stand-off would have their edges exposed by the reaming, which would allow fibrecreting onto the piles.

Final design. Consideration of all the above factors led to a recommendation for $270 \mathrm{~mm}$ diameter piles as follows:

- Vertical piles at approx $0.75 \mathrm{~m}$ centres.

- Alternating closer and further from the shaft edge; ten short piles at $0.15 \mathrm{~m}$ standoff, ten long piles at $0.5 \mathrm{~m}$ standoff.

- Alternate pile depths to $34 \mathrm{~m}$ and $44 \mathrm{~m}$.

\section{$7 \quad$ Bored pile drilling and grouting}

Drilling of the bored piles commenced in March 2007, and a great deal was learnt due to various problems encountered. The situation was complicated by time pressure to have the grouting completed, pad laid and a wider area prepared by May 2007 when the raiseboring equipment was contracted to be mobilised to site.

Two cycles of holes were drilled; refer site view Figure 8 and the plan of holes Figure 9.

First cycle of holes. The initial $270 \mathrm{~mm}$ mud drilling holes were quickly found to be unsatisfactory. Washouts of the clays occurred and the holes became blocked with mud below about $18 \mathrm{~m}$. Four of the failed holes were filled with grout only. Cable dowels were installed in the remaining six and they were grouted to the blocked depths. There were only two successful holes from this series, one to $50 \mathrm{~m}$ and the other to $35 \mathrm{~m}$. This experience resulted in the abandonment of wet drilling $270 \mathrm{~mm}$ piles.

Second cycle of holes. At short notice, the best alternative available for a second attempt was $140 \mathrm{~mm}$ reverse circulation $(\mathrm{RC})$ boreholes.

The second cycle of holes comprised two rings of $140 \mathrm{~mm} \mathrm{RC}$ drilling. The inner ring (a grout curtain) was drilled just inside the ring of failed $270 \mathrm{~mm}$ holes and filled with grout to backfill the washouts from the original drilling. The outer ring of holes was cable reinforced and replaced the failed $270 \mathrm{~mm}$ holes.

Drilling of the rings was done in one campaign, with some grout curtain holes being drilled on the same day as adjacent replacement cable holes. Grouting and drilling was done concurrently, due to:

- The proximity of the holes to each other.

- The intersection of wet zones, which are thought to have been created by the first cycle of wet drilling.

- Evidence of air from the RC drilling escaping through recently drilled neighbouring holes.

Grouting of the available open holes was usually done at the end of each shift, to allow overnight setting time before drilling recommenced on adjacent holes within the pattern. Concrete accelerator was also added to the grout as it was poured into some of the holes to speed up setting times.

The second cycle of drilling was relatively successful. Reports and evidence of the 18-28 $\mathrm{m}$ deep zones being problematic, with water and/or air flowing between open holes at these depths, coincided with the position of the poorest clay zone.

Nature of the clay. In a few of the problematic RC holes, the walls were stabilised by running the drill string up and down the hole. This may have been moulding the clay to achieve stability, which essentially plasters over any cracks that might otherwise be grouted. However on the positive side, this suggests that the clay fractured in lumps and fell into the hole, and then it could be removed. A soft clay, which flows and blocks the hole, would probably mean that an open hole could not be formed; i.e. the hole would require casing for stability, as is commonly the case during exploration drilling. 


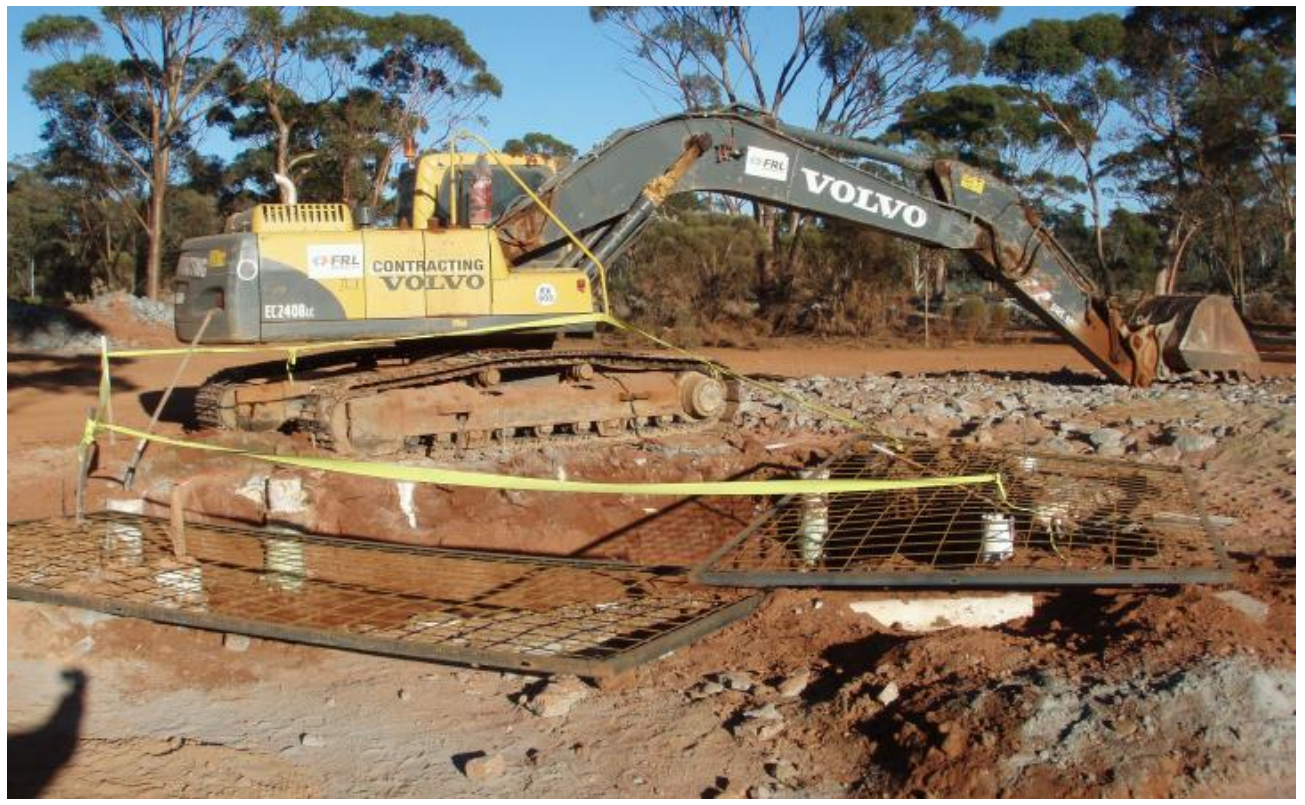

Figure 8 South raisebore site during excavation for the surface pad. The tops of several of the bored piles are visible in the walls of the excavation

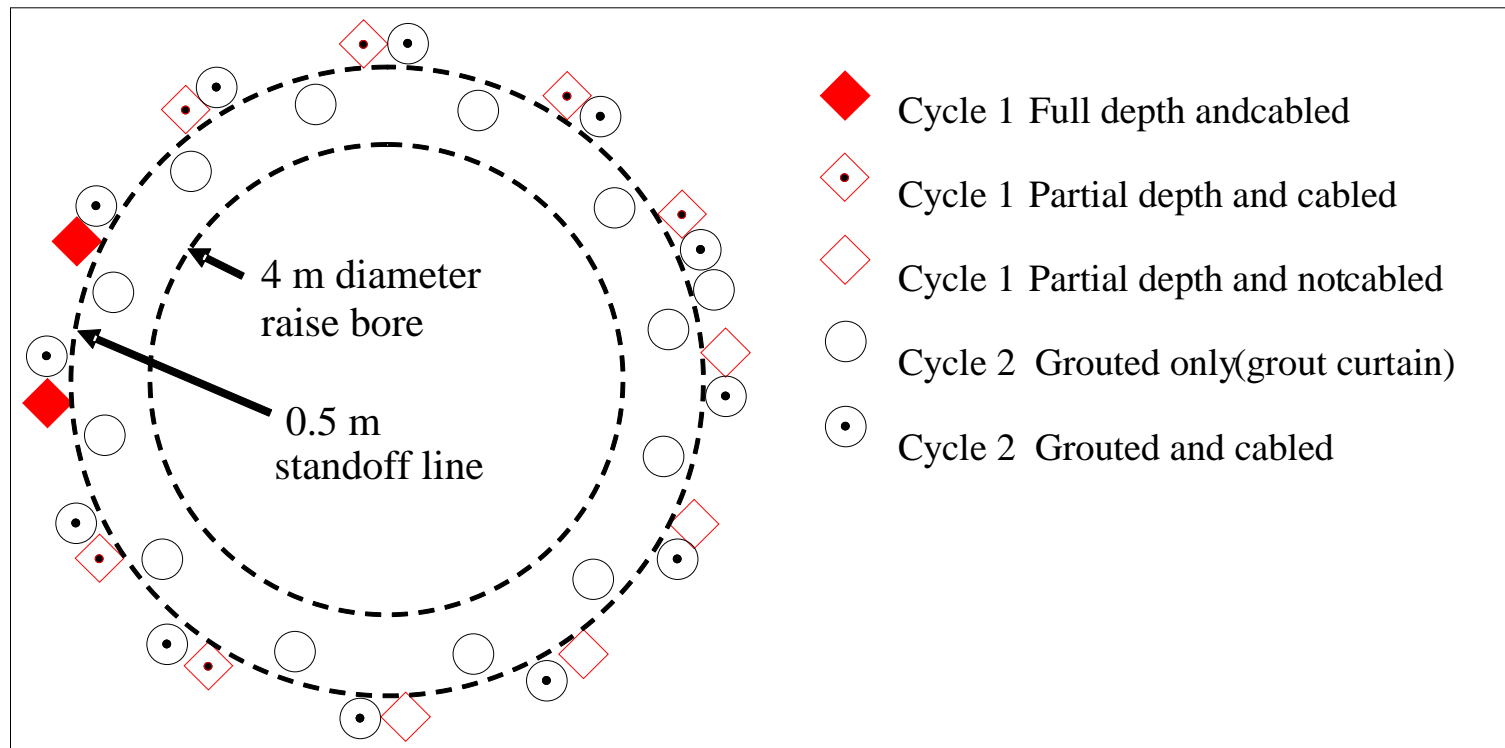

Figure 9 Schematic pile layout, showing positions of (a) the first cycle of piles, most of which failed to reach full depth, and (b) the inner and outer rings of the second cycle of piles

Problem clay distribution. The drilling reports noted intervals that were soft, blocked or closed. In total, five of the holes (only) were recorded as having problems from soft material. This suggested that the poor clay zone was not uniform, and may be a limited-width channel that happened to cut through the raisebore site.

Grout pour method. Tremmie pour of the grout was preferred, i.e. to fill the holes via positive upwards displacement, and avoid segregation of the product. However, the required pump was not available, so grout had to be poured into the top of the boreholes. Attempts were made to manage the pour rate to avoid air entrapment. This was a concern for the $140 \mathrm{~mm}$ holes with reinforcement, as there was the risk of the grout hanging and bridging. Inspection of holes 12 hours after they were filled showed significant settling and occasional 'rat-holing' of grout as it set in some holes. This suggested that entrapment of air was indeed occurring, with some air escape and settling occurring prior to the grout setting. 
Grout take in the holes. The volume of grout take in individual holes was unable to be measured accurately. Only general estimates were therefore possible as to how much grout was placed in each hole. For the first cycle of unsuccessful rotary mud boreholes, nine took less grout than expected, and in seven of those holes, grout could not be placed to the bottom of the hole because it had closed or collapsed. Subsequent grouting may not have filled any voids remaining in the clay zone.

All but one of the smaller RC holes took more grout than the nominal hole volume would allow. It is likely that the excess grout mainly occupied hole overbreak through the clay zone; i.e. clay was replaced with grout. From the excess grout take, a calculation was made of the equivalent enlarged diameter of the boreholes assuming the excess grout take was due to an over-size through the five metre long clay zone. The calculated diameters ranged from 217-495 $\mathrm{mm}$ compared to the $140 \mathrm{~mm}$ drilled size. The trends in excess grout volumes correlate very well with driller reports of which holes had soft material or blockages. The four largest oversize boreholes were exactly the same ones for which the drillers recorded soft/blocked intervals.

Cable reinforcement. Although attempts were made to install the cables centrally in the holes, by suspending them from brackets at the collar, centrality was not guaranteed. It was possible that during back-reaming, movement of the clays could push blocks of grout free of the cables.

Surface pad. The surface pad was excavated after the bored piles were completed. It intersected some of the piles as shown in Figure 10.
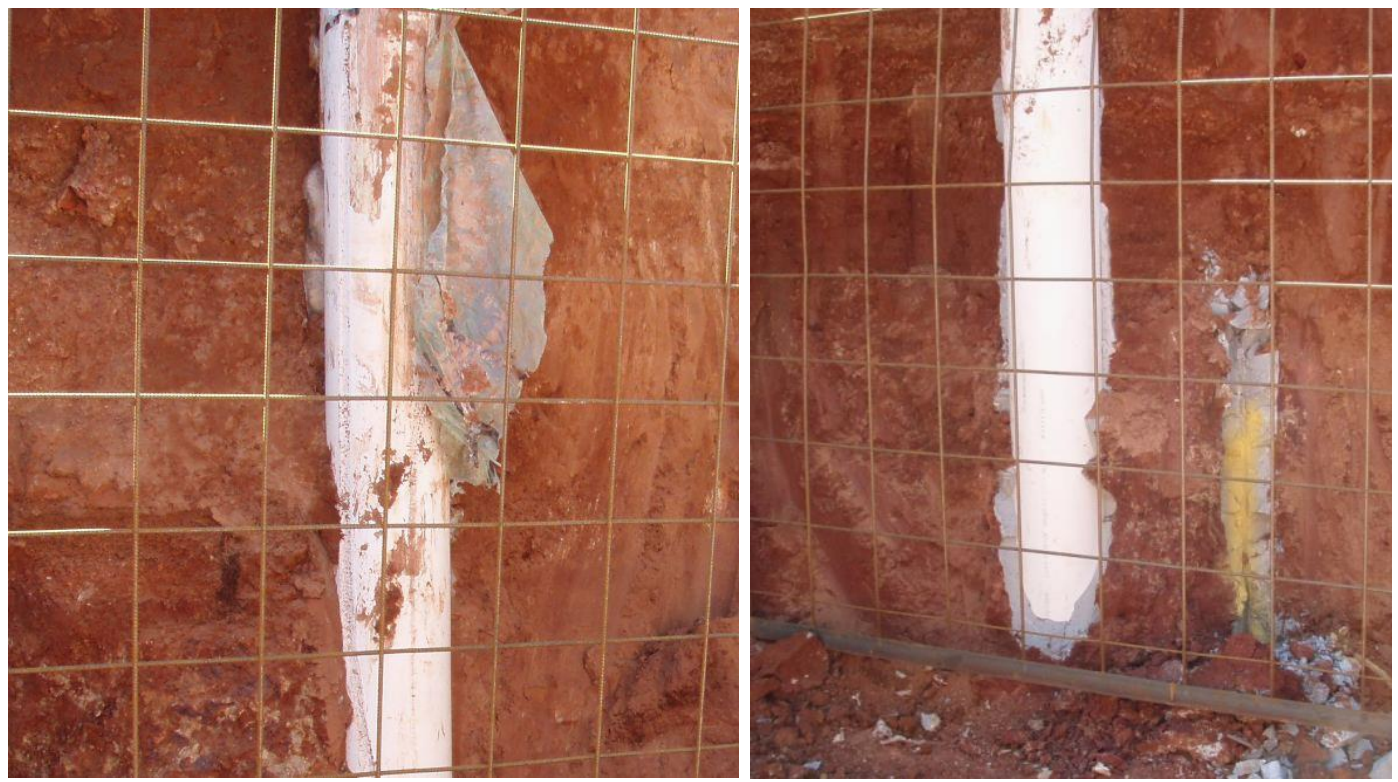

Figure 10 Some of the bored grouted piles intersected in the surface pad excavation, showing grout filling the sidewall voids created during the boring of the $\mathrm{RC}$ holes

\section{Raiseboring}

A $4.1 \mathrm{~m}$ diameter raisebore was set up, and the pilot hole was commenced on 4 June 2007 and was completed without incident. The pilot hole was dry after breakthrough, which suggested that the site was sufficiently drained. The weathered zone had to be dewatered before reaming.

Back reaming commenced on 14 June and reached the $55 \mathrm{~m}$ depth position on 27 June, where it paused for four days awaiting the expected mobilisation of the remote fibrecrete equipment to site. The $55 \mathrm{~m}$ position was chosen from the borehole log as allowing a substantial interval (pillar) from the face of the raise to the start of the weathered material at $49 \mathrm{~m}$, and also avoiding unfavourable jointing at $56 \mathrm{~m}$.

It was accepted that this was a point of no return; i.e. if a change to a smaller $1.5 \mathrm{~m}$ head was made, the raise could not subsequently be reamed to four metres. Then other methods would be needed to strip out to the final four metres. Having decided to continue at the full diameter, the final $55 \mathrm{~m}$ was then bored at a slow rate $(1 \mathrm{~m} /$ hour $)$ to minimise disturbance to the clays, damage to the piles, and to allow the remote fibrecrete equipment to be on site when the head was removed. 
It was very important that the remote fibrecreting, to support the weathered zone materials, started as soon as possible after the raise was completed and the head removed. The risks of delayed fibrecreting were timedependent destabilisation of the walls due to water inflows, and the weathered material becoming friable as it dried out following exposure to air.

The raise broke through on 3 July. Some pieces of the grout curtain piles, i.e. the central holes filled with grout, were recovered from the cuttings. No pieces of the cabled piles were found in the cuttings. The bogged volume was $95 \mathrm{~m}^{3}$ more than expected over the full shaft length. This roughly equates to the observed overbreak of the raise walls, in one area out to the piles (Figures 11 and 12). This overbreak suggests that the piles were indeed needed and that they inhibited further collapse.

\section{$9 \quad$ Fibrecreting}

The fibrecreting was unfortunately delayed for three days, and during that time further overbreak occurred from the clay zones. This greatly multiplied the highest risk period. This kind of problem needs to be resolved in any future applications of this stabilising method.

The design fibrecrete thickness was $75 \mathrm{~mm}$ generally, but $120 \mathrm{~mm}$ for the soft clay intervals. As there was reluctance to wash down the clay walls due to the wet drilling experiences, no surface preparation was done. The fibre content was $40 \mathrm{~kg}$ steel fibres per $\mathrm{m}^{3}$.

Initially, $10 \mathrm{~m}^{3}$ of fibrecrete was sprayed at the failure zone, then $75 \mathrm{~mm}$ on the full interval, starting from the collar down to fresh rock (at $50 \mathrm{~m}$ ), in three passes of $25 \mathrm{~mm}$. Rebound was found to be only about $10 \%$, so the actual fibrecrete thickness was probably nearer $130 \mathrm{~mm}$. A cavity monitoring system (CMS) survey of the raise was done after fibrecreting. It confirmed that fallout, in the main clay zone, extended out to the ring of piles (Figures 11 and 12).

\section{Discussion}

The bored piles solution was necessary and effective in this case. Overbreak of the clay up to the piles showed that the raisebore would not have been successful without the piles.

Pile drilling was a major practical problem. In hindsight, $\mathrm{RC}$ drilling in the first instance may have avoided these problems. However, the end result was 24 useful piles (compared to the 20 proposed) but $140 \mathrm{~mm}$ diameter, rather than the $270 \mathrm{~mm}$ proposed. The average spacing between the piles was about $0.5 \mathrm{~m}$, nearly the same as would have been achieved with the originally proposed larger diameter piles.

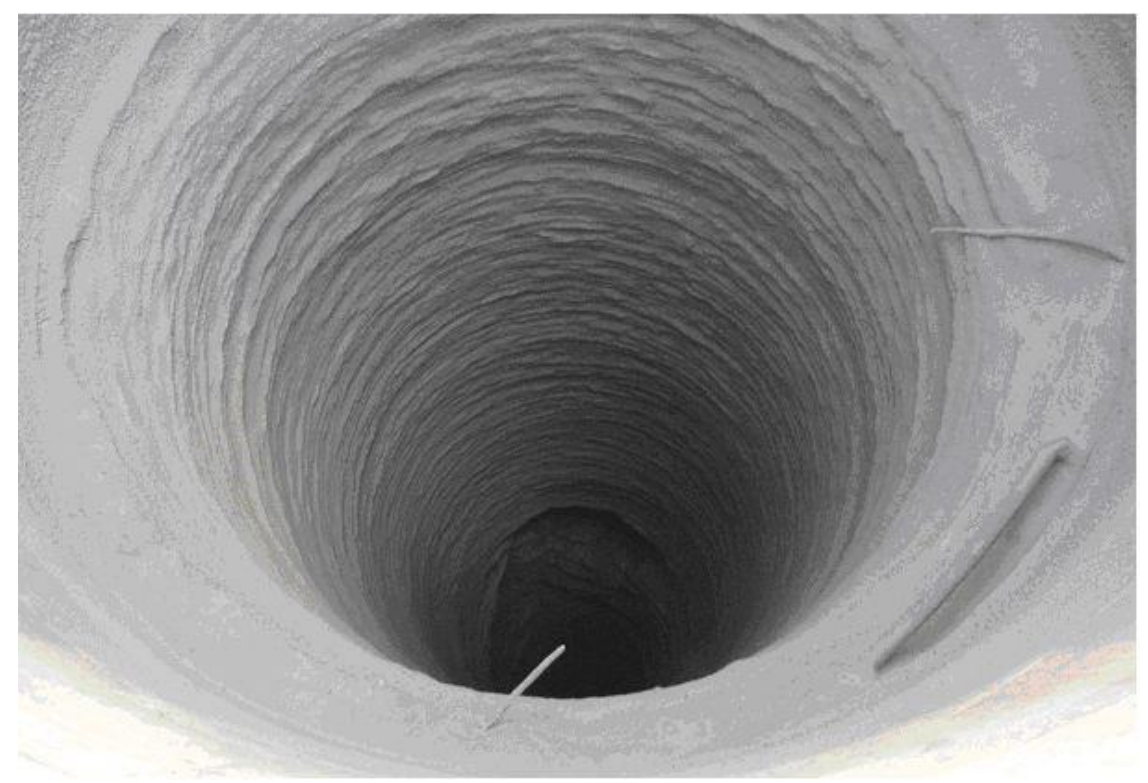

Figure 11 Completed shaft after fibrecreting — note the widened zone below $20 \mathrm{~m}$ 


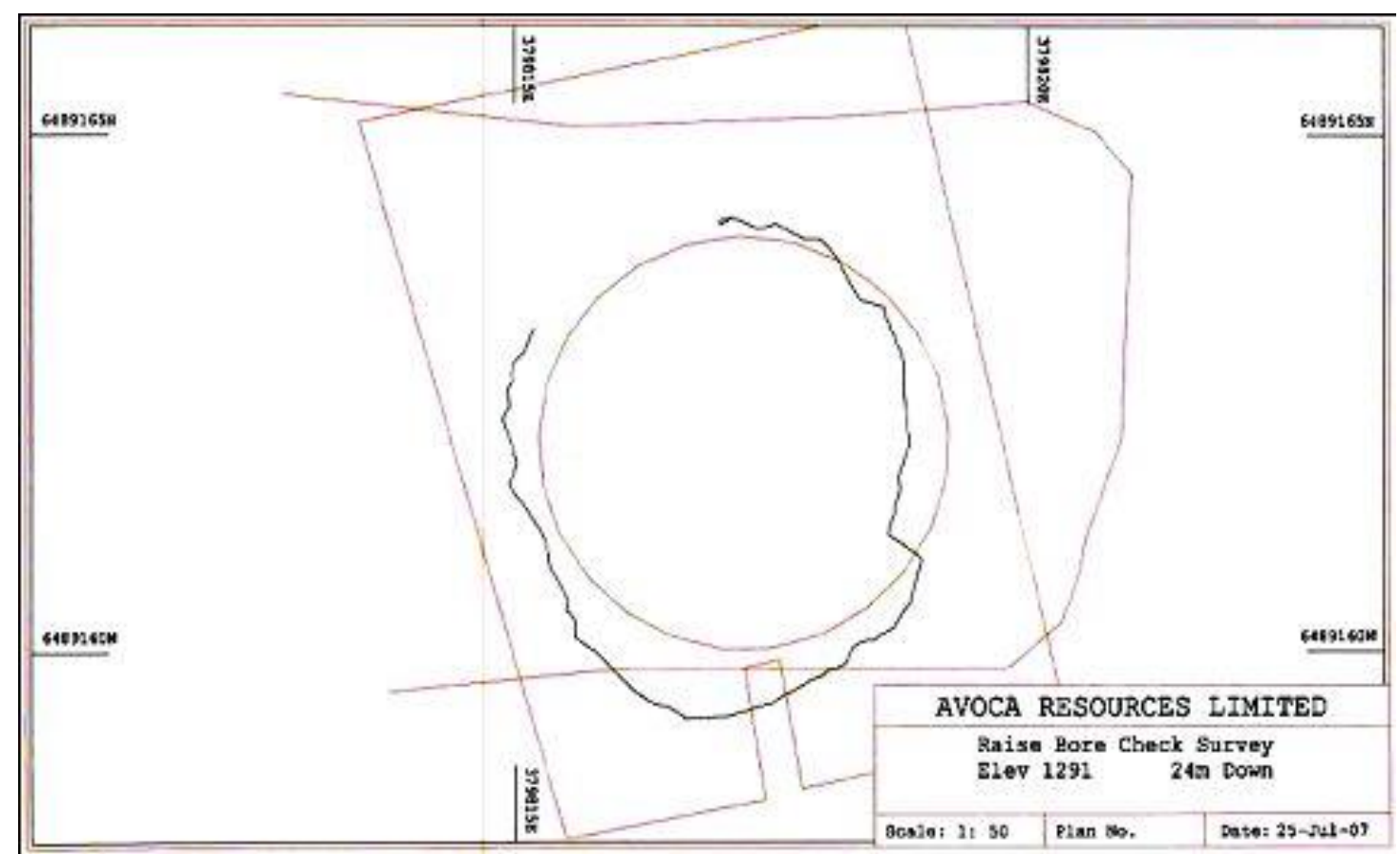

Figure 12 CMS survey profile of the completed shaft at the widened zone $24 \mathrm{~m}$ below surface

Based on this experience, the critical elements for a future application of a bored-pile-supported raisebore design would include:

- Choose a method of drilling holes that will:

$\circ$ Ensure a minimum risk of disruption to the material type being drilled.

- Allow a series of closely spaced holes to be drilled cleanly, without connections between open holes.

- Source grouting equipment so that:

- Grout can be placed in holes via a positive placement method, to ensure that air is not entrapped during grouting.

- The quantity of grout placed in each hole can be accurately measured.

- Good planning, in terms of personnel, equipment procurement and time factors.

- Good site supervision of works, in terms of experience and knowledge.

\section{Acknowledgements}

The authors gratefully acknowledge the Trident site managers, engineers and operators for their support, and Avoca Resources for permission to publish this paper.

\section{References}

Barton, N., Lien, R. and Lunde, J. (1974) Engineering Classification of Rock Masses for the Design of Tunnel Support, Rock Mechanics, Vol. 6, No. 4, May 1974, pp. 189-236.

McCracken, A. and Stacey, T.R. (1989) Geotechnical Risk Assessment of Large Diameter Raise-bored Shafts, Shaft Engineering Conference, Inst Min Met, pp. 309-316.

Peck, W.A. and Lee, M.F. (2008) Stability of Raise Bored Shafts in Australian Mines, 13th Australian Tunnelling Conference, Melbourne, 4-7 May. 